Collective Interviewing: Eliciting Cues to Deceit using a Turn-Taking Approach Zarah Vernham ${ }^{1}$

Aldert Vrij

Samantha Mann

Sharon Leal

Jackie Hillman

University of Portsmouth

\footnotetext{
${ }^{1}$ Correspondence concerning this article should be addressed to: Zarah Vernham, University of Portsmouth, Psychology Department, King Henry Building, King Henry 1 Street, Portsmouth, PO1 2DY, UK, or via e-mail: zarah.vernham@port.ac.uk.
} 


\begin{abstract}
Group interviewing provides useful insight into the social indicators of deception. The present study investigated turn-taking as a technique for enhancing novel cues to deceit. 'Turn-taking' is a technique whereby the interviewer states which of the two interviewees is to answer the question and then intervenes every 20 seconds by stopping whichever of the interviewees is responding and asking the other interviewee in the pair to continue from the point in which their partner was stopped. In the present experiment, truth tellers were real couples who had been in relationship for at least one year and cohabiting. Lying pairs were friends who pretended to be in a relationship for at least one year and cohabiting. All 'couples' were interviewed together in their pairs about their real or fictitious relationship. It was found that when forced to turn-take, truth telling pairs were significantly more able to continue on from one another, whereas lying pairs were significantly more likely to repeat what their partner last said before continuing. Additionally, lying pairs waited before speaking after being told to turn-take significantly more than truth telling pairs. A subsequent lie detection study revealed that these three turn-taking cues improved people's ability to accurately detect deceit considerably. Implications for simultaneous interviewing are discussed.
\end{abstract}

Keywords: deception, turn-taking, collective interviewing, cognitive load, lie detection. 


\section{Collective Interviewing: Eliciting Cues to Deceit using a Turn-Taking Approach}

Deception research has primarily focused on interviewing single suspects despite the fact that crimes are frequently committed by pairs or multiple offenders (Van Mastrigt \& Farrington, 2009; $\mathrm{M}^{\mathrm{c}}$ Gloin \& Piquero, 2009). One reason for interviewing suspects individually is that police detectives traditionally separate suspects as soon as possible prior to interrogation to reduce opportunity for planning of responses (Kassin \& Gudjonsson, 2004). Consequently, several studies that have considered pairs of truth tellers and pairs of liars have involved interviewing group members individually (e.g., Granhag, Strömwall \& Jonsson, 2003; Strömwall, Granhag \& Jonsson, 2003; Vrij et al., 2009). Despite individual interviewing reflecting many real-life police interviewing contexts, there are several field settings in which collective interviewing (interviewing of two or more individuals together at the same time) would be more suited. For example, when there are multiple suspects but only one interviewer available, such as during police stop and searches, at road border controls where cars containing several people are checked, or at security checkpoints (e.g., airports). In such settings it would make logical sense to interview people together about joint activities, because it would be a more timely and convenient means of gathering intelligence. Each year more than 200 million people cross the UK Border, and each year the UK Border Agency checks over 100 million people arriving at UK airports and consider around 3.5 million applicants to visit, live, work and study in the UK (Home Office UK Border Agency, 2011-2015). Securing border control and controlling migration is important not only in the UK, but also worldwide, for identifying threats from organised crime, terrorism, smuggling, trafficking, and illegal immigration each of which frequently involves groups of individuals (Home Office UK Border Agency, 2010). Sometimes collective interviewing is part of an existing procedure for security reasons. For example, in Canada custom officers carry out collective interviews at airports because groups are deemed to have 'similar issues', 
and therefore if only one person in the group is examined then this could result in a wasted effort or a missed opportunity (personal communication with A. Leach, a Canadian excustoms officer, $12^{\text {th }}$ November 2013).

Also, in the UK the situation occurs whereby one member of a couple is British and the other needs to seek British Citizenship in order to be with their partner. In order to marry and achieve citizenship couples are expected, at one potential stage, to be interviewed simultaneously. It is estimated that around 35,000 marriages in the UK every year involve a non-European Economic Area (EEA) national. The Home Office estimates that between 4,000 and 10,000 applications to stay in the UK are made on the basis of sham marriages (marriages of convenience whereby the couple are not genuine) (Home Office, 2013). Sham marriages are on the increase, and they frequently involve individual facilitators or organised crime groups that increase the profits for criminal activity (Home Office, 2013). If a sham marriage is uncovered it often leads to imprisonment with the non-EEA national being arrested and removed from the UK (Home Office, 2013). Due to the increasing problems and risks associated with immigration, the present study explored the application of collective interviewing in an obtaining citizenship interview setting. The study was divided into two experiments, the first experiment identified three unique cues that emerge when a turn-taking manipulation is implemented into a collective interview, and the second experiment explored whether observers can recognise these cues to discriminate between pairs of truth tellers and pairs of liars.

\section{Collective Interviewing}

Collective interviewing is different from individual interviewing. Collective interviewing will determine deception at a social level rather than just at an individual level, and will enable the identification of cues to deceit that are present in groups, but cannot be 
explored in individuals, e.g. cues stemming from suspects communicating and interacting with one another.

Recently, four studies have illustrated the clear potential for using collective interviewing to elicit cues to deceit. Vrij et al. (2012) found that pairs of truth tellers interrupted and corrected each other more than pairs of liars, as well as adding more information to each other's accounts in comparison to pairs of liars. Jundi et al. (2013a) found that pairs of liars made more eye contact with the interviewer than pairs of truth tellers, whereas pairs of truth tellers looked more at each other than pairs of liars. Driskell, Salas and Driskell (2012) found that pairs of truth tellers illustrated more synchrony in behaviour and exhibited more interactions (e.g., mutual eye gaze and verbal transitions) than pairs of liars, and Jundi, Vrij, Hope, Mann and Hillman (2013b) found that, compared to lying pairs, truth telling pairs posed more questions to one another during a timeline task.

These four studies show that a collective approach can generate discrepancies between pairs of truth tellers and pairs of liars that can aid in the detection of deception, with communication cues and interaction cues (e.g., corrections, interruptions, eye contact, verbal transitions) being particularly indicative of deceit. Corrections, interruptions and verbal transitions are unique to collective interviewing and cannot be measured when individuals are interviewed. Eye contact with the interviewer, of course, can be measured in individuals. However, whereas eye contact is not a diagnostic cue to deceit in individuals (DePaulo et al., 2003) it is a diagnostic cue to deceit when pairs of interviewees are interviewed (Jundi et al., 2013a). A possible reason why, in collective interviews, truth tellers display less eye contact with interviewers than liars is that in collective interviews truth tellers communicate more with each other than liars, and when people communicate with each other they tend to look at each other (Jundi et al., 2013a). In sum, collective interviewing is different from interviewing 
individuals; thus cues that are not diagnostic of deceit when individuals are interviewed may become diagnostic of deceit when dyads or groups are interviewed.

\section{Memory: Collaborative and Transactive}

A collective interview approach coincides with the upcoming trend in memory research which is starting to focus on collaborative learning and remembering. Collaborative memory refers to how people collectively recall information alongside others (Rajaram \& Pereira-Pasarin, 2010), and can be applied to deception research, particularly the strategies that truth tellers and liars employ. When pairs of truth tellers are asked to recall a shared event, they exhibit interactions that cannot be unveiled when interviewed individually and these interactions tend to occur more frequently for the truth telling pairs than for the lying pairs. Truth tellers prefer a 'tell it all' strategy that aims to provide a detailed description of what actually occurred (Granhag et al., 2003; Strömwall et al., 2003; Vrij, Mann, Leal \& Granhag, 2010a). Pairs of truth tellers will collectively recall information by sharing their experiences and communicating with one another (e.g., by posing questions to one another or correcting each other's accounts) (Jundi et al., 2013b; Vrij et al., 2012).

Liars' dominant strategy is to prepare answers to possible questions and to keep their stories simple (Granhag et al., 2003; Strömwall et al., 2003; Vrij et al., 2010a). Therefore, lying pairs tend to exhibit fewer interactions as they merely recall their fabricated story (Driskell et al., 2012; Vrij et al., 2012). In addition, when answering unexpected questions to which they have not prepared an answer for, lying pairs need to rely on their individual cognitive ability to create a story that makes sense and matches with what their partner is saying (Wegner, 1987). This latter activity can be mentally-taxing and this cognitive load can be further increased by forced turn-taking.

\section{Imposing Cognitive Load through Turn-Taking}


Previous deception research with individual liars and individual truth tellers has attempted to introduce new interview strategies that focus on the different psychological states experienced by liars and truth tellers. One of the strategies identified is 'imposing cognitive load', which has been found to elicit and magnify verbal and nonverbal cues to deception making the differences between liars and truth tellers more pronounced (Vrij, Fisher, Mann \& Leal, 2008). Lying is often more mentally-taxing than truth telling (Zuckerman, DePaulo \& Rosenthal, 1981), and perhaps particularly in interview settings, in part because lying includes more tasks than truth telling. Liars focus on their story telling, but also on making a convincing impression and scrutinizing the interviewer to check whether they believe them (Buller \& Burgoon, 1996). Truth tellers merely focus on their story telling (Buller \& Burgoon, 1996). Consequently, liars have fewer cognitive resources left over to cope when mentally-taxing interventions are implemented into the interview schedules (Vrij et al., 2008).

When recalling information as a pair or group, the group members interact with each other resulting in a naturally occurring turn-taking pattern (Sacks, Schegloff, \& Jefferson, 1974). This pattern emerges when one person speaks then stops, and then another person continues then stops, and the sequence is repeated with the other person then taking over again. This cyclical sequence back and forth between members of the group only finishes once all members have nothing else left to say. Turn-taking automatically shapes the communication and reporting of information amongst the group members, and consists of two essential characteristics: (1) frequency which refers to the amount of times turn-taking occurs; and (2) control of contribution which refers to the amount of control each individual has over what to say and how much to say (Woodburn, Arnott, Newell, \& Procter, 1991). The present experiment exploited this naturally occurring turn-taking speech pattern by introducing a mentally-taxing intervention whereby the interviewer forced turn-taking 
between the pairs within the collective interview. Forced turn-taking meant that the interviewer stopped whichever member of the pair was recalling, and asked the other member in the pair to continue from the point in which their partner was stopped. They did this repeatedly between the members until the pair had finished answering the interview question.

Forced turn-taking instigates social interactions between pairs of interviewees and should be more cognitively demanding for lying pairs than for truth telling pairs for several reasons. First, pair members are required to concentrate on what they are saying as well as what their partner is saying; the latter may be mentally difficult when the partner is telling a fabricated story. Second, forced turn-taking takes away pair members' ability to choose who answers each of the questions, removing the effects of any dominant characters who tend to speak more frequently (Hung et al., 2007), an effect that is often present within close relationships (Dunbar \& Burgoon, 2005). In lying pairs, it means that the pair member who is most eloquent or most comfortable with lying loses the ability to control the interview. Third, interrupting somebody's turn has been found to violate the natural flow of recall and inhibit the ability of the individual to continue with their turn (Coates, 2004). Finally, forced turntaking removes any retrieval strategy adopted by the pairs (Basden, Basden, Bryner \& Thomas III, 1997). If the question is unanticipated and one person in the pair is forced to fabricate, the other individual in the pair is then forced to continue with that fabrication, hence it requires the members of the pair to have rapid thinking and good improvisation skills (Vrij, Granhag \& Mann, 2009). If the pair lacks such skills, they will have difficulty continuing on from one another, requiring them to create more time to think before providing new information. Therefore, cues reflecting increased cognitive demand such as repetitions and waiting will be valuable in deception detection.

Lying pairs are already using more cognitive resources than truth telling pairs, and the forced turn-taking technique will place a higher level of cognitive load onto each member of 
the pair. Consequently, forced turn-taking will be more demanding for lying pairs than truth telling pairs which will result in cues to deceit emerging, some of which have not yet been identified in deception research: continuations and repetitions. Speech onset delays' (waiting) is also likely to emerge when forced turn-taking is implemented.

\section{Deception Cue: Number of Details}

Deception research with individuals has found that individual truth tellers provide significantly more details when recalling events than individual liars (DePaulo et al., 2003; Vrij, 2008; Vrij, Granhag \& Porter, 2010b). As a result, it is worthwhile to consider whether number of details remains a significant cue to deceit when more than one individual is interviewed together at the same time, and also when the turn-taking technique is implemented. We cannot think of any theoretical reasons as to why number of details will not be a cue to deceit in collective interviews. As is the case in individual interviews, in collective interviews truth tellers should find it easier to provide details and should not fear that the extra detail will incriminate them. Overall, we believe turn-taking will act as a stimulant to say more and so all pairs (truth tellers and liars) will feel they need to provide extra information when the interviewer asks them to swap and continue with the story. This is a similar notion to that postulated in Leal, Vrij, Warmelink, Vernham and Fisher (2013) who found that when a very detailed model statement was played to participants prior to them giving their own statements, number of details within the statements from both truth tellers and liars increased. We believe that differences between truth tellers and liars in the amount of details which are likely to arise in the non-turn-taking questions should also theoretically arise in the forced turn-taking questions.

\section{Experiment 1: Hypotheses}

The overall aim of the present experiment was to investigate whether we could identify important cues to deceit and enhance the detection of deception in 'couples' (i.e. 
pairs) by forcing turn-taking (as a way of increasing cognitive load) into the interview schedule. It is hypothesised that forced turn-taking will impose cognitive load and thus be more difficult for lying pairs compared to truth telling pairs. Consequently, truth telling pairs will be significantly more able than lying pairs to instantly continue on from one another when forced to turn-take; whereas lying pairs, perhaps to buy time on what to say, will be significantly more likely than truth telling pairs to repeat what their partner last said before continuing when forced to turn-take (Hypothesis 1). Additionally, as a result of cognitive load, it is hypothesised that lying pairs will be significantly more likely than truth telling pairs to wait (i.e. pause) when forced to turn-take by the interviewer (Hypothesis 2). It is also hypothesised that the turn-taking interview questions will elicit more details than the nonturn-taking interview questions from the truth telling and lying pairs together (Hypothesis 3 ). Based on the frequent research that shows that individual truth tellers provide significantly more details when recalling information than individual liars (Vrij et al., 2010b), it is also predicted that the total number of details provided will remain significantly greater for pairs of truth tellers than pairs of liars regardless of whether the interview question involves the forced turn-taking technique (Hypothesis 4).

\section{Experiment 1: Method}

\section{Participants}

A total of 92 participants (45 males and 47 females) from the University of Portsmouth took part in this study. The mean age was 22.64 years $(S D=5.90)$. A t-test revealed that age significantly differed between truth telling pairs $(M=24.77$ years, $S D=$ $7.02)$ and lying pairs $(M=20.32$ years, $S D=3.04), t(65.23)=4.005, p<.001$; however when age was used as a covariate in all the proceeding analyses it did not change any of the experimental findings reported in the Results section. Truth telling pairs $(\mathrm{N}=24)$ were real couples who had been in a relationship for at least one year and cohabiting. Lying pairs $(\mathrm{N}=$ 
22) were friends who were told only to take part as a pretend couple if they had never been intimate with one another and did not live together. The lying pairs had to be of the same sexual orientation; thus of the opposite sex to one another if they were both heterosexual and of the same sex if they were both homosexual. Of all 46 pairs who participated in this study, 45 were heterosexual and one was homosexual. The one homosexual pair was a lying couple.

\section{Design}

This study used a mixed design with Veracity (truth versus lie) as the betweensubjects factor and Turn-taking (absent versus present) as the within-subjects factor. Which three of the six questions were used as turn-taking questions differed for each pair and was controlled for so that the truth telling group and the lying group were matched on turn-taking combinations. This counterbalancing technique removed any effects of question order from influencing the findings; thus any significant differences found between pairs of truth tellers and pairs of liars would be a result of the forced turn-taking manipulation itself, not the order in which the turn-taking questions occurred.

\section{Procedure}

Upon arrival to the Psychology Department, all pairs were asked to go for coffee (paid for by the researchers) for approximately 30 minutes. They were instructed to prepare during coffee for the interview and talk about their 'real' or 'pretend' relationship, discussing (i) how they met, (ii) how they spend time together, and (iii) where they live (the interview then focused on these issues). They were also informed that they would be interviewed together at the same time. Therefore, if differences between truth tellers and liars were to emerge, this would not be because the collective interview setting took the pairs by surprise. Once the pairs returned to the department and stated they were ready to be interviewed, they individually completed pre-interview questionnaires. The pre-interview questionnaire asked participants to rate on 7-point Likert scales the sufficiency (ranging from [1] insufficient to 
[7] sufficient), quality (ranging from [1] very poor to [7] very good), and usefulness (ranging from [1] = pointless to [7] = useful) of their preparation discussion. It also asked the participants to rate how much they discussed with their partner what to say during the interview (ranging from [1] not at all to [7] = thoroughly).

A collective interview in which pairs were interviewed together then took place. The interview was audio- and video- recorded. All interviews involved one interviewer who was blind to the veracity of the couple. The interview schedule comprised six interview questions (see Table 1) and included the turn-taking manipulation which took place in three questions.

Insert Table 1 about here

Forced turn-taking worked as follows: The interviewer stated which of the two participants was to answer the question (each participant was asked to start answering on one of the questions and on the third occasion the pair could choose who started answering), and then intervened every 20 seconds by stopping whichever of the participants was responding and asking the other participant in the pair to continue from the point in which their partner was stopped. This continued until the pair had finished answering the question. Therefore, although each participant only had 20 seconds (time-frame decided based upon two previous pilot studies) on each turn to provide details, they could have as many turns as they wanted, and could continue providing detail until they indicated they no longer could take a turn and had no more information to give in response to the interview question. Each of the questions in Table 1 were possible forced turn-taking questions, and which three questions were used for forced turn-taking and which three were not was counterbalanced for each pair (hence turn-taking was a within-subjects manipulation). The three questions that did not involve the forced turn-taking manipulation instead promoted spontaneous speech and natural turntaking. The task for all couples was to convince the interviewer that they were a bona fide couple who had been in a relationship for at least one year and were now living together. 
Thus real couples just had to tell the truth, whilst pretend couples had to describe a fabricated relationship.

To motivate participants to perform well during the experiment, they were told that if they were believed by the interviewer they would receive $£ 5$. However, if they were not believed they would receive no money and would be required to write a statement about their relationship with the other individual in their pair.

Following participation, a post-interview questionnaire was completed individually and at this stage all participants were instructed to be truthful about their experience of the interview and the strategies they used. In this questionnaire, participants were asked to rate on a 7-point Likert scale from [1] not at all motivated to [7] extremely motivated, the extent to which they felt motivated to appear convincing during the interview. They were also asked to rate their confidence in receiving $£ 5$ and their confidence about whether or not they would have to write a statement (both on 7-point Likert scales from [1] not at all likely to [7] very likely).

Truth tellers were asked an additional open question about how long, in number of months, they had been in a romantic relationship with their interview partner. This relationship length variable was used in correlation analyses along with each of the turntaking dependent variables as a means of examining whether or not relationship length was associated with any of the dependent variables, and therefore confounding the effect of veracity.

Conversely, liars were given an additional post-interview questionnaire to explore whether they actually met the inclusion criteria and had not been in a previous intimate relationship with their interview partner. The first part of this questionnaire asked an open question about how long, in number of months, the liars had been friends with one another. It then measured on four different 7-point Likert scales how they rated their friendship with 
their interview partner. This included questions about friendliness (ranging from [1] strangers to [7] best friends), intimacy (ranging from [1] distant to [7] intimate), importance (ranging from [1] unimportant to [7] important) and trustfulness (ranging from [1] distrusting to [7] trusting). Each individual that made up the lying pair gave their own rating for each of the four questions. The ratings from the four questions were then added together to give a total friendship-closeness rating for each individual within each pair. The average rating for each pair was obtained providing an overall friendship-closeness score for each lying pair. The friendship length and the friendship-closeness variables were inputted into correlation analyses along with each of the turn-taking dependent variables to determine whether friendship length or friendship-closeness were associated with any of the dependent variables, and therefore confounding the effect of veracity.

To ensure that all participants were actually paid $£ 5$, the experimenter told them at the end of the experiment (following the post-interview questionnaires) that the interviewer believed they were telling the truth.

\section{Coding}

The interviews were each transcribed, and the interview transcripts coded by a rater who was blind to the hypotheses and veracity status of the pairs. Each of the six questions were coded separately.

The dependent variables: (1) number of swaps instigated by interviewer, (2) continuations when swapping, (3) repetitions when swapping, and (4) waiting before continuing or repeating after swapping were coded only for the three interview questions in which the turn-taking manipulation was implemented. Number of swaps instigated by interviewer was the number of times the interviewer forced turn-taking between the pair. Continuations when swapping and repetitions when swapping measured the smoothness in which the pair were able to swap when forced to turn-take by the interviewer. If the pair were 
able to instantly (i.e. without pausing or repeating previous information) continue on from one another when the interviewer forced swapping then this was counted as a continuation when swapping and the pair was given a score of 1 (the absence of a continuation was given a score of 0 ). If, when being forced to turn-take, the member of the pair taking over first repeated any of the information that their partner last said before continuing with the story then this was counted as a repetition when swapping and the pair was given a score of 1 (the absence of a repetition was given a score of 0 ).

Waiting before continuing or repeating after swapping was an objective measure based on whether each member of the pair immediately continued or repeated after swapping, or paused (e.g. 'err', 'umm', 'erm', or a gap of non-speech for three seconds or longer) before continuing or repeating after swapping. This was a dichotomous variable, that is if the participant paused or stuttered when forced to take over from their partner, then this was counted as waiting and a score of 1 was given (if there was no waiting, a score of 0 was given). The frequency of each of these turn-taking variables was computed for each pair.

To take into account the number of swaps instigated by the interviewer, the turntaking dependent variables, (1) total number of continuations when swapping, (2) total number of repetitions when swapping, and (3) total number of times members of the pair waited before continuing or repeating after swapping, were divided by the total number of swaps for each pair during the forced turn-taking questions. This created three new dependent variables that were inputted into the analyses: (1) average number of continuations per swap; (2) average number of repetitions per swap; and (3) average number of times participants waited before continuing or repeating per swap.

Verbal cues were coded using the total number of details provided for both the turntaking and non-turn-taking interview questions. This meant that three different frequencies could be computed: (i) total number of details for all six interview questions; (ii) total number 
of details for the three turn-taking questions only; and (iii) total number of details for the three non-turn-taking questions only. A detail was coded only if it was new information that had never been said previously by either member of the pair.

A second coder, also blind to the hypotheses and veracity status of the pairs, coded 16 of the 46 transcripts for each of the dependent variables: (1) total number of swaps instigated by interviewer, (2) total number of continuations when swapping, (3) total number of repetitions when swapping, (4) total waiting before continuing or repeating after swapping, and (5) total number of details. Intra-class correlation coefficients (ICCs) were then calculated between the two individual raters for each of the five dependent variables. The inter-rater reliability between the two coders was very good with each of the ICCs demonstrating good agreement between the two raters (swaps instigated by interviewers: ICC $=1.00$; continuations when swapping: $\mathrm{ICC}=.94$; repetitions when swapping: $\mathrm{ICC}=.83$; waiting before continuing or repeating after swapping: $\mathrm{ICC}=.86$; number of details: $\mathrm{ICC}=$ $.95)$.

\section{Experiment 1: Results}

\section{Pre-Interview Questionnaire}

Four one-way ANOVAs were conducted to examine if there was a significant difference between truth tellers and liars in terms of how they rated their preparation discussion prior to being interviewed. There was no significant difference between truth tellers and liars in terms of how they rated their preparation discussion in terms of sufficiency $\left(F(1,90)=0.011, p=.918, e^{2} a^{2}=.000\right)$, and being $\operatorname{good}\left(F(1,90)=0.959, p=.330, e^{2} a^{2}=\right.$ $.011)$. However, liars rated the preparation discussion as more useful $(M=5.89, S D=.97$, $95 \% \mathrm{CI}[5.41,6.36])$ than truth tellers $(M=4.15, S D=1.99,95 \% \mathrm{CI}[3.69,4.60]), F(1,90)=$ $27.645, p<.001$, eta $^{2}=.235$. Liars also stated that they discussed with their partner about what to say during the interview significantly more thoroughly $(M=5.45, S D=.90,95 \% \mathrm{CI}$ 
$[5.06,5.89])$ than truth tellers $(M=3.86, S D=1.62,95 \%$ CI $[3.47,4.24]), F(1,90)=33.304$, $p<.001, e t a^{2}=.270$.

\section{Post-Interview Questionnaire: Motivation, Manipulation Checks, Collective Interviewing and Forced Turn-Taking}

The vast majority of participants indicated that they were motivated to appear convincing during the interview, with $80.3 \%$ of the sample scoring 5 or higher on the 7-point Likert scale. Liars were significantly more motivated $(M=6.09, S D=.86,95 \%$ CI [5.60, 6.58]) than truth tellers $(M=4.85, S D=2.10,95 \% \mathrm{CI}[4.39,5.32])$ to appear convincing, $F$ $(1,90)=13.188, p<.001$, eta $^{2}=.128$. In terms of confidence, truth tellers reported that they were more confident $(M=6.04, S D=1.37,95 \%$ CI $[5.61,6.48])$ than liars $(M=4.48, S D=$ $1.68,95 \%$ CI $[4.02,4.93])$ that they would receive $£ 5, F(1,90)=24.206, p<.001$, eta $^{2}=$ .212. Truth tellers also believed they were less likely $(M=2.71, S D=1.73,95 \%$ CI [2.26, 3.16]) than liars $(M=4.36, S D=1.40,95 \% \mathrm{CI}[3.89,4.84])$ to have to write a statement, $F$ $(1,90)=25.262, p<.001, e^{2} a^{2}=.219$.

\section{Hypotheses Testing}

Turn-Taking Variables. A one-way ANOVA was conducted examining the difference between truth tellers and liars in terms of the total number of swaps instigated by the interviewer during the turn-taking questions. There was no significant difference between truth tellers $(M=8.83, S D=8.00,95 \%$ CI $[5.94,11.73])$ and liars $(M=9.05, S D=5.78,95 \%$ CI $[6.03,12.07])$ with regard to the total number of swaps, $F(1,44)=.010, p=.919$, eta ${ }^{2}=$ .000 .

A one-factor between-subjects MANOVA was conducted with Veracity (truth versus lie) as the only factor and average number of continuations per swap, average number of repetitions per swap, and average number of times participants waited before continuing or repeating per swap as the dependent variables. The MANOVA revealed a significant 
multivariate main effect for Veracity, Wilks' $\lambda=.290, F(3,42)=34.207, p<.001$, eta $^{2}=$ .710. Additionally, significant univariate main effects for Veracity were obtained for the average number of continuations per swap, $F(1,44)=10.419, p=.002$, eta $^{2}=.191$; average number of repetitions per swap, $F(1,44)=56.945, p<.001$, eta $^{2}=.564$; and average number of times participants waited before continuing or repeating per swap, $F(1,44)=$ 24.818, $p<.001$, eta $^{2}=.361$. Truth tellers were able to continue their story significantly more often than liars when instructed to swap by the interviewer $(M=.70, S D=.35,95 \%$ CI $[.58$, $.82]$ and $M=.43, S D=.19,95 \% \mathrm{CI}[.31, .55]$, respectively), whereas liars were significantly more likely to repeat what their partner last said then continue when instructed to swap by the interviewer $(M=.52, S D=.21,95 \%$ CI $[.45, .60])$, in comparison to truth tellers $(M=.13$, $S D=.14,95 \%$ CI $[.06, .21])$. This supports Hypothesis 1. Furthermore, when asked to swap by the interviewer liars waited before speaking significantly more often than truth tellers $(M$ $=.71, S D=.24,95 \%$ CI $[.60, .82]$ and $M=.33, S D=.27,95 \%$ CI $[.22, .43]$, respectively), supporting Hypothesis 2.

Three discriminant analyses were conducted on each of the three significant turntaking variables separately to investigate the nature of their relationship with Veracity. The discriminant analyses revealed that all three turn-taking variables were individually significant predictors of Veracity when number of swaps was once again taken into consideration (see Table 2). The cross-validated classification results revealed high accuracy rates (around the $80 \%$ mark) for all three variables.

Insert Table 2 about here

\section{Verbal Cues: Total Number of Details}

A mixed-design ANOVA was conducted with the turn-taking manipulation as the within-subjects factor, comprising two levels: total number of details within the three turntaking questions for each pair and total number of details within the three non-turn-taking 
questions for each pair. Veracity was the between-subjects factor. Turn-taking had a significant effect on the total number of details provided by each pair, $F(1,44)=7.992, p=$ .007, eta $^{2}=.154$, with all pairs together providing significantly more details on the turntaking questions $(M=209.54, S D=103.73,95 \%$ CI $[178.74,240.35])$ compared to the nonturn-taking questions $(M=168.02, S D=94.31,95 \%$ CI $[140.01,196.03])$. This supports Hypothesis 3. Veracity also had a significant effect on the total number of details provided by each pair, $F(1,44)=4.052, p=.050$, $e t a^{2}=.084$, with pairs of truth tellers $(M=424.75, S D$ $=183.02,95 \%$ CI $[356.44,493.06])$ providing significantly more details overall than pairs of liars $(M=326.09, S D=145.20,95 \%$ CI $[254.74,397.44])$. The Turn-Taking X Veracity interaction effect was not significant, $F(1,44)=.207, p=.651$, eta $^{2}=.005^{2}$.

\section{Truth Telling Pairs Relationship Status}

Pearson's correlation analyses were conducted to test the association between relationship length and each of the turn-taking dependent variables. The correlations revealed that there were no significant associations between relationship length $(M=41.92, S D=$ 44.74), and total number of swaps, $r(22)=-.101, p=.638$; average number of continuations per swap, $r(22)=.230, p=.280$; average number of repetitions per swap, $r(22)=-.109, p=$ .612 ; and average number of times participants waited before continuing or repeating per swap, $r(22)=.243, p=.252$. Hence, no links were found between relationship length and turn-taking.

\section{Lying Pairs Friendship Status}

\footnotetext{
${ }^{2}$ Despite the interaction effect not being significant, a significant difference was found between pairs of truth tellers and pairs of liars in terms of how many details they provided in the non-turn-taking questions, $F(1,44)=4.358, p=.043$, eta ${ }^{2}=.090$, but not in terms of how many details they provided in the turn-taking questions, $F(1,44)=1.978, p=.167$, eta ${ }^{2}$ $=.043$. Hypothesis 4 cannot be supported.
} 
Analyses from the liars' self reports about how friendly they actually were as a pair indicated that the lying pairs reported being friendlier than was desired for the inclusion criteria of this study. That is, they were recruited as a pair only if they stated they were friends who were of the same sexual orientation, who had never been intimate, never been in a romantic relationship, and never lived together. However, liars obtained a mean of 5.73 (SD $=.95,95 \% \mathrm{CI}[5.44,6.02])$ for friendliness on a Likert scale of 1 (strangers) to 7 (best friends); a mean of $4.91(S D=1.25,95 \%$ CI $[4.53,5.29])$ for intimacy on a Likert scale of 1 (distant) to 7 (intimate); a mean of $5.91(S D=1.07,95 \%$ CI $[5.58,6.24])$ for the importance of their friendship with their interview partner on a Likert scale of 1 (unimportant) to 7 (important); and a mean of $6.07(S D=1.21,95 \% \mathrm{CI}[5.70,6.44])$ for how trusting they were of their partner on a Likert scale of 1 (distrusting) to 7 (trusting). Despite this, the results were still significant, demonstrating that even when good friends lie together, cues to deceit still emerge in a collective interview situation. This strengthens the effect Veracity had on each of the dependent variables. Furthermore, Pearson's correlation analyses were conducted to test the association between friendship-closeness and each of the turn-taking dependent variables. The correlations revealed that there were no significant associations between friendship-closeness $(M=22.61, S D=3.27)$, and total number of swaps, $r(20)=-.304, p=$ .169 ; average number of continuations per swap, $r(20)=-.174, p=.438$; average number of repetitions per swap, $r(20)=.208, p=.352$; and average number of times participants waited before continuing or repeating per swap, $r(20)=-.040, p=.859$.

Pearson's correlation analyses were also conducted to test the association between friendship length and each of the turn-taking dependent variables. The correlations revealed that there were no significant associations between friendship length $(M=14.39, S D=$ 14.30), and total number of swaps, $r(20)=-.071, p=.754$; average number of continuations per swap, $r(20)=-.017, p=.941$; average number of repetitions per swap, $r(20)=-.043, p=$ 
.851 ; and average number of times participants waited before continuing or repeating per swap, $r(20)=.053, p=.813$. These analyses suggest that neither friendship-closeness nor friendship length were related to turn-taking.

\section{Experiment 1: Discussion}

\section{Hypotheses 1 and 2: Turn-Taking Variables}

Truth telling pairs were able to continue their story significantly more often than lying pairs when forced to swap by the interviewer, whereas lying pairs were significantly more likely than truth telling pairs to repeat what their partner last said when forced to swap by the interviewer (Hypothesis 1). Additionally, lying pairs were significantly more likely than truth telling pairs to wait before speaking when the interviewer forced turn-taking (Hypothesis 2). Forced turn-taking eliminates the interviewee's control, removes any retrieval strategies the pair are using (Basden et al., 1997), and disrupts the natural flow of recall, inhibiting the individuals' ability to spontaneously continue when forced to swap (Coates, 2004). The ability to continue on from one another when forced to turn-take is easier for truth tellers because they both actually experienced the event and know what one another are reporting. They are using their memory to collectively recall a shared event (Rajaram \& Pereira-Pasarin, 2010). Conversely, liars face difficulty in this forced turn-taking and buy themselves time by waiting before speaking and by repeating what their interview partner last said.

The combination of waiting and repetition, displayed by liars, further demonstrates how difficult the forced turn-taking task was for them. It provides insight into liars' metacognition about making a credible impression. Liars are probably aware that waiting too long before answering makes a suspicious impression on observers (The Global Deception Team, 2006; Strömwall, Granhag \& Hartwig, 2004; Vrij, Akehurst \& Knight, 2006), and they therefore decide not to wait too long. However, since they still do not know what to say they buy further time by repeating what the other person had said. 


\section{Hypotheses 3 and 4: Number of Details and Turn-Taking}

The pairs of participants provided significantly more details on the turn-taking questions than the non-turn-taking questions (Hypothesis 3). The increased number of details from the turn-taking interview questions is likely to be because the pairs felt they needed to provide extra information when the interviewer forced them to swap and continue with the story. This turn-taking technique thus acted as a hidden stimulation to say more. This is similar to Leal et al. (2013) who found that presenting a very detailed model statement increased the amount of detail reported by both truth tellers and liars. Truth tellers used the model statement to get an idea of the types of information they needed to provide, which increased their recall. Apparently, liars also felt they needed to talk more as a response to the detailed model statement. This is for investigative interviewing an important finding because the main aim of such interviews is to gather information (Bull, 2010; Fisher, 2010; Meissner, Redlich, Bhatt \& Brandon, 2012). If a technique can be implemented into the interview schedule that results in more details being provided by truth tellers, it gives investigators more opportunity to check that their statement is correct. In the case of liars, it will increase the chances of them 'slipping up' and saying information that is incriminating.

Pairs of truth tellers did provide significantly more details than pairs of liars on the non-turn-taking questions. This is consistent with previous research that has frequently found number of details to be a significant cue when distinguishing individual truth tellers from individual liars (DePaulo et al., 2003). This is not surprising because like individual truth tellers, pairs of truth tellers actually experienced the event so the recall of information is less difficult and the truth tellers do not fear that any extra detail will incriminate them (Vrij, 2008). Lying pairs, on the other hand, are fabricating their story making it more difficult to recall. They are also fearful of saying something that will incriminate them. 
Pairs of truth tellers and pairs of liars provided a similar number of details when answering the turn-taking interview questions (rejecting Hypothesis 4). Since number of details successfully discriminated between pairs of truth tellers and pairs of liars in the nonturn-taking questions but not in the turn-taking questions this suggests that forced turn-taking makes the cue 'number of details' less reliable. We do not think this is problematic. First, since 'number of details' remained a cue to deceit in the non-turn-taking questions, investigators can introduce forced turn-taking in conjunction with non-turn taking, so that in the non-turn taking questions the investigators focus on detail and in the forced turn-taking questions they focus on the turn-taking dependent variables. In addition, it could be argued that there will be a cognitive overload for an investigator to focus on the three turn-taking dependent variables as well as on the total number of details in the forced turn-taking questions, making examining the number of details perhaps redundant when turn-taking is implemented.

\section{Experiment 2: Discriminating Between Truths and Lies}

The fact that collective interviewing reveals new cues to deceit that have not yet been identified does not automatically mean that observers will be able to discriminate better between pairs of truth tellers and pairs of liars when they are informed about the turn-taking cues. This second experiment therefore investigated whether the turn-taking cues developed during the first experiment could be accurately identified so that laypersons could correctly classify pairs based upon their veracity. This is a relevant addition to the research as someone could argue that the cues obtained in the first experiment are only relevant if observers are able to spot these cues. We believe that the cues - continuations, repetitions and waiting - can be easily recognised allowing for observers to accurately discriminate between the pairs and detect deceit. Therefore, it is hypothesised that observers being informed about continuations, repetitions and waiting during the turn-taking interview questions will be 
better able to discriminate between pairs of truth tellers and pairs of liars compared to observers who only have access to the non-turn-taking interview questions or who have access to the turn-taking interview questions but are not informed about the turn-taking cues (Hypothesis 5).

\section{Experiment 2: Method}

\section{Participants}

A total of 90 observers with a mean age of 35.33 years $(S D=13.41)$ took part in this study, 40 were male and 50 were female. Of the 90 observers, 29 were single, 25 were in a relationship, 5 were engaged, and 31 were married. An analysis of covariance demonstrated that the relationship status of the observers had no effect on the results obtained in this second experiment. All observers who took part in this lie detection experiment were volunteers who were not compensated for participating. Additionally, they had not partaken as part of any couple in the first experiment.

\section{Design}

This study used a 3 x 2 between-subjects design with Condition (non-turn-taking versus turn-taking control versus turn-taking cues) as the first between-subjects factor and Veracity (truth versus lie) as the second between-subjects factor. A total of 90 observers were randomly allocated to one of three conditions (30 observers in each condition). Observers read only one interview transcript consisting of three interview questions with responses from either one 'real' (truth telling) or one 'pretend' (lying) couple. Hence, within each condition 15 observers judged a lying couple and 15 different observers judged a truth telling couple. Of the 46 transcripts obtained in Experiment 1, one truth telling pair and one lying pair were used as examples leaving 44 transcripts to be judged in Experiment 2 consisting of 21 lying pairs and 23 truth telling pairs. Each transcript was divided into two parts: A non-turn-taking part and a turn-taking part. This resulted in 21 lying non-turn-taking parts, 23 truth telling 
non-turn-taking parts, 21 lying turn-taking parts, and 23 truth telling turn-taking parts. In Condition 1 (non-turn-taking), observers were required to judge veracity when the turn-taking technique was not implemented, whereas in Conditions 2 (turn-taking control) and 3 (turntaking cues) the turn-taking manipulation was implemented. For condition 1 (non-turntaking) 15 of the 21 lying transcripts and 15 of the 23 truth telling transcripts were randomly used. For conditions 2 and 3 (turn-taking), 30 lying transcripts and 30 truth telling transcripts were needed (60 in total) from the 21 lying and 23 truth telling transcripts available (44 in total). This meant that a random sample of 16 turn-taking transcripts were used twice in conditions 2 and 3, but no transcript was used twice in the same condition. That is, the same transcript could be used in conditions 2 and 3 but never twice in condition 2 or twice in condition 3.

\section{Procedure}

Observers were recruited using an opportunity sample and asked to read and sign an informed consent form. They first completed a few demographic details and were then allocated to one of the three conditions and given instructions to read depending on what condition they were allocated. All instructions told the observers about the first experiment stating that truth telling couples and lying couples had been interviewed in pairs about their 'real' or 'pretend' relationship and that their task was to now read a transcript and judge the veracity of the pair being questioned in their transcript. The instructions then described specific cues the observers were to look for depending on their condition.

In Condition 1 (non-turn-taking), observers were told that number of details often distinguishes truth tellers from liars [an accurate fact, DePaulo et al., 2003] with truth tellers providing more details than liars. They were informed of the different types of details that may be present and shown an example response from both a truth telling pair and a lying pair in which different types of details were highlighted (see Appendix A). They were then 
required to read one transcript that did not include the turn-taking manipulation and asked to judge, based on number of details, whether they thought the pair being interviewed were a truth telling couple or a lying pair.

In Condition 2 (turn-taking control), observers were again told that number of details often distinguishes truth tellers from liars with truth tellers providing more details than liars. They were informed about the turn-taking manipulation and of the different types of details that may be present. They were then shown an example response from both a truth telling pair and a lying pair when turn-taking was implemented into the interview schedule, and the different types of details were again highlighted (see Appendix B). They were then required to read one transcript with the turn-taking manipulation present. Observers were once again asked to judge, based on number of details, whether they thought the pair being interviewed were a truth telling couple or a lying pair. This instruction meant that the observers in conditions 1 and 2 were asked to judge detail globally and subjectively, rather than objectively through counting every single detail. Research has demonstrated that observers can make accurate subjective judgements of the number of details that appear in a statement (Vrij, Evans, Akehurst \& Mann, 2004).

In Condition 3 (turn-taking cues), observers were informed about the turn-taking manipulation and instructed to look out for three turn-taking cues: continuations, repetitions and waiting. Each of the cues were defined and the observers were informed that continuations tend to occur more often amongst truth telling pairs whereas repetitions and waiting tend to occur more often amongst lying pairs. They were provided with an example response from both a truth telling pair and a lying pair when turn-taking was implemented into the interview schedule. Each of the three cues were highlighted on the examples (see Appendix C). They were then asked to read one transcript that included the turn-taking manipulation and asked to judge, based on the three turn-taking cues, whether they thought 
the pair being interviewed were a truth telling couple or a lying pair. Each of the turn-taking cues were not explicitly stated within the transcripts that the observers were asked to read; instead observers merely used the definitions of the cues they were provided with to identify whether the cues were present in their transcript. Waiting was illustrated on the transcripts by utterances such as "erm" and "umm" or by “..." (which was indicative of a pause of three seconds or longer).

In all conditions observers were asked to report what cues they had used to make their veracity judgement. This was an open-ended question recorded qualitatively. Participation took approximately 15 minutes.

Interview transcripts were chosen as the materials of this lie detection study (as opposed to video clips) because we wanted to be sure the observers focused only on the verbal content of what the pairs were saying as opposed to the nonverbal content and how the pair behaved. By focusing on the text/speech only, the pure effect and the potential of the turn-taking manipulation could be observed without the observers being influenced by other factors.

The cues reported to have been used by the 90 observers were coded and computed per condition. A total of 13 different cues were mentioned by the observers: number of details, unnecessary details, continuations, repetitions, waiting, consistency, plausibility, feelings, equality, lack of memory, cross-checking of information, own relationship beliefs, and natural interactions. Each cue could only be mentioned once by each observer. To measure the reliability of the coding, a second rater coded the cues reported by 24 observers (eight observers from each condition). An inter-rater reliability analysis, using the Kappa statistic, revealed high agreement between the two raters in allocating the cues to the 13 categories $($ Kappa $=.683, p<.001)$. Manipulation checks were conducted to explore what cues observers were using in each of the three conditions. Additionally, both truth accuracy 
(truth transcripts) and lie accuracy (deceptive transcripts) were measured for all 90 observers by giving the observer a 1 if their veracity judgement was correct and a 0 if their veracity judgement was incorrect.

\section{Experiment 2: Results}

\section{Manipulation check: What cues do observers use to make their veracity judgement?}

To explore what cues the observers were using to make their veracity judgement, a MANOVA was conducted with Condition (non-turn-taking versus turn-taking control versus turn-taking cues) as the only factor and each of the 13 cues as the dependent variables. The MANOVA revealed a significant multivariate main effect for Condition, Wilks' $\lambda=.276, F$ $(26,150)=5.205, p<.001, e t a^{2}=.474$. Additionally, significant univariate main effects for Condition were obtained for six of the 13 cues (see Table 3).

Insert Table 3 about here

Tukey post-hoc tests revealed significant differences between condition 1 (non-turntaking) and condition 3 (turn-taking cues) for four of the six significant cues: number of details, continuations, repetitions, and waiting. Significant differences were also found between condition 2 (turn-taking control) and condition 3 (turn-taking cues) for all six of the significant cues. There were no significant differences between condition 1 (non-turn-taking) and condition 2 (turn-taking control) in terms of the cues used (see Table 3). Observers reported to have used the appropriate cues (as instructed) in each of the conditions. That is, observers in conditions 1 and 2 used number of details as their cue to judging veracity significantly more than those in condition 3, whereas the observers in condition 3 used continuations, repetitions and waiting as their cues to judging veracity significantly more than those in conditions 1 and 2.

\section{Hypothesis Testing: Lie Detection Experiment}


The overall accuracy rate was $57.8 \%$ across all three conditions (truth accuracy $=$ $60.0 \%$, lie accuracy $=55.6 \%$ ). A $3 \times 2$ between-subjects ANOVA was conducted with Condition (non-turn-taking versus turn-taking control versus turn-taking cues) as the first between-subjects factor, Veracity (truth versus lie) as the second between-subjects factor, and accuracy rate as the dependent variable. The ANOVA revealed a significant univariate main effect for Condition, $F(2,84)=3.384, p=.039$, eta ${ }^{2}=.075$. There was no significant main effect for Veracity, $F(1,84)=.185, p=.668$, eta $^{2}=.002$, nor was there a significant Condition X Veracity interaction effect, $F(2,84)=.325, p=.724$, eta $^{2}=.008$. Observers in 'Condition 1 non-turn-taking' obtained an accuracy rate of $46.7 \%$ (truth accuracy $=53.3 \%$, lie accuracy $=40.0 \%$ ), observers in 'Condition 2 turn-taking control' obtained an accuracy rate of $50 \%$ (truth accuracy $=53.3 \%$, lie accuracy $=46.7 \%$ ), and observers in 'Condition 3 turn-taking cues' obtained an accuracy rate of $76.7 \%$ (truth accuracy $=73.3 \%$, lie accuracy $=$ $80.0 \%)$. The total accuracy rate in Condition $3(M=.77, S D=.43,95 \%$ CI $[.593, .941])$ was significantly higher than the total accuracy rate in Condition $1(M=.47, S D=.51,95 \% \mathrm{CI}$ $[.293, .641]), F(1,56)=5.968, p=.018$, eta $^{2}=.096$, and the total accuracy rate in Condition $2,(M=.50, S D=.51,95 \%$ CI $[.325, .675]), F(1,56)=4.667, p=.035, e^{2} a^{2}=$ .077. The difference in total accuracy rate between Conditions 1 and 2 was not significant, $F$ $(1,56)=.063, p=.803$, eta $^{2}=.001$. These findings support Hypothesis 5.

\section{Experiment 2: Discussion}

Experiment 2 demonstrated that asking participants to use the turn-taking cues to detect deception facilitated their ability to discriminate between pairs of truth tellers and pairs of liars. Participants who were given a transcript involving the turn-taking manipulation and instructed to look for the three turn-taking cues (continuations, repetitions, waiting) were better at distinguishing between truth telling pairs and lying pairs than those participants who were not given the turn-taking manipulation or were given the turn-taking manipulation but 
not informed of the three turn-taking cues (Hypothesis 5). In fact, the accuracy rate for both truths $(73.3 \%)$ and lies $(80 \%)$ were very high for the observers who were informed about the turn-taking cues and amongst the highest accuracy rates ever found in verbal lie detection research, see Vrij (2008) for overviews of such research.

These high accuracy rates reflect the clear potential of forced turn-taking on the ability to distinguish between pairs of truth tellers and pairs of liars. Demonstrating its true potential is necessary, but this is only a first step. The next logical step would be to examine what accuracy rates would be achieved in real-life interviews. Until then, caution should be made when interpreting the high accuracy levels, because we cannot say for definite whether similar accuracy rates will be obtained in such real-life interviews. Perhaps real-life interviews will enable investigators to discriminate between lies and truths even better than when interview transcripts are used, because a strong, yet unidentified, diagnostic cue to deceit could emerge in such settings in addition to the cues examined in the present experiment. Alternatively, the real-time interviews will create noise and will lead to lower accuracy rates, either through the interpretation of non-diagnostic nonverbal cues or because the observers will use their own first impression of the pair to judge whether they are a real or pretend couple (Ambardy \& Skowronski, 2008; Carney, Colvin \& Hall, 2007).

\section{General Discussion}

We examined the use of a collective interviewing approach in the detection of deception, with a turn-taking manipulation being implemented within the interview to increase cognitive load. It was found that turn-taking elicited novel and detectable cues to deceit that significantly discriminated between pairs of truth tellers and pairs of liars. These cues were continuations, repetitions and waiting, and each achieved impressive accuracy levels.

\section{Additional Forced Turn-Taking Manipulations}


The forced turn-taking technique used in the present study clearly elicited new cues that were indicative of deceit in pairs of interviewees. However, there are implications for further manipulations using the forced turn-taking technique. First, more than two interviewees could be interviewed at the same time and the turn-taking implemented amongst all group members. We expect the same findings as we found here, because such a situation will not change the underlying principle of forced turn-taking. Second, interviewees could be informed that forced turn-taking is going to take place and it could be examined how this affects the variables identified in the present study and/or the strategies employed by truth tellers and liars. In terms of strategy, the problem liars have is that they do not know which questions will be asked. However, to 'beat' the forced turn-taking manipulation, they should come up with a strategy that also works when questions are asked that they have not expected. We think this will be a challenging task. Third, instructions could be implemented into the turn-taking manipulation, for example, by telling the pairs or groups that they must not repeat information when asked to swap and/or that they must swap as quickly as possible. This should further enhance the cognitive load that liars experience when confronted with forced turn-taking.

\section{Additional Collective Interview Settings and Manipulations}

Future studies should consider alternative settings in which collective interviewing could be implemented. For example: police 'stop and search' scenarios, insurance claims, road border control, and security checkpoints. We think that the findings of the present study could be applied to other environments because the theoretical rationale on which the findings are based (i.e. cognitive load) will remain the same regardless of the setting in which two or more people are being interviewed together. Additionally, it would be interesting to explore the effect that the turn-taking manipulation has when multiple witnesses are interviewed together at the same time, as opposed to multiple suspects. 
To emphasise, we are not suggesting collective interviewing should replace individual interviewing. Instead we suggest that it be employed as a 'new' or 'additional' approach to individual interviewing. Therefore, the collective interview could be used in isolation whereby if the group raises suspicion in a collective interview, investigators take the required actions they would normally take after interviewing individuals who raise suspicion (e.g. calling for assistance, collecting further evidence). Alternatively, collective interviewing could act as an initial screening process to determine whether suspects then need to be interviewed individually. Collective interviewing is not just limited to pairs; it can also be applied when interviewing more than two suspects.

The present study assumed equal status between the pairs. In real life, situations occur in which one member has a higher status with a greater degree of responsibility and esteem than the other member. Future studies should consider pairs or groups with varying degrees of status to explore how this influences collective interview situations. In addition, in real-life it could be that an alibi backs up the story of a suspect, by pretending to be with the suspect at a given time when this was not the case. In this example, the alibi can be truthful about their activities, whilst the suspect has to completely lie about their activities. Importantly, although suspect-alibi situations may have an effect on natural turn-taking, we do not think that it will influence forced turn-taking, as in the latter situation the pair members can no longer control which pair member provides which piece of information.

\section{Methodological Considerations}

Two methodological issues deserve further discussion. First, with hindsight it is perhaps unfortunate that the status of the truth teller's relationship was not documented. That is, the degree to which the truth tellers were intimate, friendly, trusting, and important to one another was not recorded as it was with the lying pairs in the study. Truth telling couples are likely to differ on these four 'closeness' variables depending on how they feel within their 
relationship and on the stage they are at within their relationship (e.g., engagement vs. marriage; children vs. no children); therefore it could be that intimacy, friendliness, trustfulness, and importance influence truth teller's ability to continue each other's train of thought when forced to turn-take. Had the truth tellers been asked more about their relationship at the time of the experiment then degree of intimacy, friendliness, trustfulness, and importance could have been used as control variables strengthening the findings obtained. Nevertheless, the length of the relationship (which is perhaps an indicator of relationship stage) was recorded, and analyses of relationship length demonstrated that this was not associated with the truth telling pairs ability to take turns. In addition, although relationship-closeness was not measured in truth tellers, it was measured in liars but did not correlate with any of the turn-taking dependent variables, implying that relationshipcloseness is not associated with a pairs' ability to take turns.

Second, the truth telling pairs always told a story about their real romantic relationship, whereas the lying pairs always told a false story about a fictitious romantic relationship. This means that not only did veracity differ between the two conditions, but so did relationship status. Therefore, it may well be that the findings obtained were due to truth telling pairs having more experience of communicating shared events with one another. Despite this, the lying pairs were friends who were closer to one another and more familiar with one another than required to meet the study criteria (as shown in the Results section). This strengthens the findings obtained. Furthermore, neither the friendship-closeness nor the friendship length of the lying pairs were associated with turn-taking. Hence, it would seem that it is veracity that influences turn-taking ability, not relationship status. Using pairs of individual liars who were friends and familiar with one another makes the study more applicable to real-life whereby pairs pretending to be in a relationship, e.g., during immigration interviews, are likely to be known to each other, and not complete strangers. 


\section{Policy Implication}

The main aim for immigration agencies is to distinguish between genuine couples and fake couples. Given the high number of marriages that involve a non-EEA national believed to be a sham $(4,000-10,000$ in the UK; Home Office, 2013), and the connection that sham marriages have with organised crime groups and increased criminality, it is important to reduce the chances of these occurring. In 2013, the Home Office identified the need for increased interviewing of immigration applicants to help "root out abuse of British visas and improve the integrity of our immigration system" (pp. 48). When the genuineness of a relationship is being investigated, documentary evidence is examined, the couple are interviewed in-depth and/or a home visit will occur. It is during the investigative stages that techniques need to be implemented in order to detect potential sham relationships and prevent them from occurring. Collective interviewing and the implementation of forced turn-taking is one method that could increase the detection accuracy of genuine and fake relationships, and this is important because it will help with the identification of sham relationships and with the possible prosecution of those who may be involved in criminal activity (including organised crime, trafficking, perjury, facilitating or conspiring to illegal immigration).

\section{Theoretical Implications}

The present study fills in a gap within the deception literature whereby group deceit has been ignored. Specifically, this research provides support for previous collective interviewing studies into deception (e.g. Driskell et al., 2012; Jundi et al., 2013a,b; Vrij et al., 2012) and shows the potential for exploring the social indicators of deception as well as the individual indicators.

Additionally, a collective approach fits well with the upcoming research in the memory literature which focuses on collective memory and collaborative recall (e.g., Barnier \& Sutton, 2008; Blumen, Rajaram \& Henkel, 2013; Harris, Paterson \& Kemp, 2008). Of 
particular relevance to the current study is that of transactive memory theory which postulates that people who are actually in a close relationship (truth tellers) share remembering (Wegner, 1987), knowing one another's memory expertise - That is each person in the pair knows what they are to remember as well as what the other person in their pair is to remember (Hollingshead \& Brandon, 2003). Consequently, encoding, storing and recalling information is more interactive and communicative between members of a pair that are recalling an actual shared event compared to a pair that are recalling a fabricated event. These interactive and communicative behaviours during joint recall have been associated with the development of other cues indicative of truthfulness, including posing questions to one another, providing cues to one another, handing over remembering responsibility, and finishing each other's sentences (Vernham, Vrij, Leal, Mann \& Hillman, 2014).

\section{Conclusion}

The present study demonstrated that forced turn-taking can be an efficient method for eliciting cues to deceit, and that these cues can only be detected within a collective interview setting whereby two or more individuals are interviewed together at the same time.

Continuations when turn-taking, repetitions when turn-taking, and waiting when turn-taking, are important cues to deceit which are easy and quick for investigators (and laypersons) to notice.

\section{References}

Ambardy, N., \& Skowronski, J.J. (2008). First Impressions. New York: Guildford Press. Barnier, A.J., \& Sutton, J. (2008). From Individual to Collective Memory: Theoretical and Empirical Perspectives. Memory, 16, 177-182. DOI: 10.1080/09541440701828274.

Basden, B. H., Basden, D. R., Bryner, S., \& Thomas III, R. L. (1997). A comparison of group and individual remembering: Does collaboration disrupt retrieval strategies? Journal 
of Experimental Psychology. Learning, Memory, and Cognition, 23, 1176-1189. DOI: 10.1037/0278-7393.23.5.1176.

Blumen, H.M., Rajaram, S., \& Henkel, L. (2013). The Applied Value of Collaborative Memory Research in Aging: Behavioral and Neural Considerations. Journal of Applied Research in Memory and Cognition, 2, 107-117.

DOI:10.1016/j.jarmac.2013.03.003.

Bull, R. (2010). The investigative interviewing of children and other vulnerable witnesses:

Psychological research and working/professional practice. Legal and Criminological Psychology, 15, 5-24. DOI: 10.1348/014466509X440160.

Buller, D. B., \& Burgoon, J. K. (1996). Interpersonal Deception Theory. Communication Theory, 6, 203-242. DOI: 10.1111/j.1468-2885.1996.tb00127.x.

Carney, D.R., Colvin, C.R., \& Hall, J.A. (2007). A thin slice perspective on the accuracy of first impressions. Journal of Research in Personality, 41, 1054-1072. DOI: 10.1016/j.jrp.2007.01.004.

Coates, J. (2004). Women, Men and Language: A Sociolinguistic Account of Gender Differences in Language ( $3^{\text {rd }}$ Ed.). Longman: Harlow.

DePaulo, B. M., Lindsay, J. J., Malone, B. E., Muhlenbruck, L., Charlton, K., \& Cooper, H. (2003). Cues to Deception. Psychological Bulletin, 129, 74-118. DOI: 10.1037/00332909.129.1.74.

Driskell, J.E., Salas, E., \& Driskell, T. (2012). Social Indicators of Deception. Human Factors: The Journal of the Human Factors and Ergonomics Society, 54, 577-588. DOI: $10.1177 / 0018720812446338$.

Dunbar, N.E., \& Burgoon, J.K. (2005). Perceptions of Power and Interactional Dominance in Interpersonal Relationships. Journal of Social and Personal Relationships, 22, 207233. DOI: $10.1177 / 0265407505050944$. 
Fisher, R. P. (2010). Interviewing Cooperative Witnesses. Legal and Criminological Psychology, 15, 25-38. DOI: 10.1348/135532509X441891.

The Global Deception Team. (2006). A World of Lies. Journal of Cross-Cultural Psychology, 37, 60-74. DOI: 10.1177/0022022105282295.

Granhag, P.A., Strömwall, L.A., \& Jonsson, A.C. (2003). Partners in Crime: How Liars in Collusion Betray Themselves. Journal of Applied Social Psychology, 33, 848-868. DOI: 10.1111/j.1559-1816.2003.tb01928.x.

Harris, C.B., Paterson, H.M., \& Kemp, R.I. (2008). Collaborative Recall and Collective Memory: What happens when we remember together? Memory, 16, 213-230. DOI: 10.1080/09658210701811862.

Hollingshead, A. B., \& Brandon, D.P. (2003). Potential Benefits of Communication in Transactive Memory Systems. Human Communication Research, 29, 607-615. DOI: 10.1111/j.1468-2958.2003.tb00859.x.

Home Office. (2013). Sham Marriages and Civil Partnerships: Background information and proposed referral and investigation scheme. Retrieved from: https://www.gov.uk/government/uploads/system/uploads/attachment_data/file/256257 /Sham_Marriage_and_Civil_Partnerships.pdf.

Home Office UK Border Agency. (2010). Protecting our Border, Protecting the Public: The UK Border Agency's five year strategy for enforcing our immigration rules and addressing immigration and cross border crime. Retrieved from: http://webarchive.nationalarchives.gov.uk/20100303205641/http:/www.ukba.homeoff ice.gov.uk/sitecontent/documents/managingourborders/crime-strategy/protectingborder.pdf?view=Binary. 
Home Office UK Border Agency. (2011-2015). UK Border Agency Business Plan: Securing our Border, Controlling Migration. Retrieved from:

http://www.ukba.homeoffice.gov.uk/sitecontent/documents/aboutus/uk-borderagency-business-plan/business-plan/ukba-business-plan?view=Binary.

Hung, H., Jayagop, D., Yeo, C., Friedland, G., Ba, S., Odobez, J.M., Ramchandran, K., Mirghafori, N., \& Gatica-Perez, D. (2007, September). Using Audio and Video Features to Classify the Most Dominant Person in a Group Meeting. Paper presented at the ACM 15th international conference on Multimedia, New York. Retrieved from: http://www.idiap.ch/ftp/papers/2007/hung-MM-2007.pdf.

Jundi, S., Vrij, A., Hope, L., Mann, S., \& Hillman, J. (2013b). Establishing Evidence through Undercover and Collective Intelligence Interviewing. Psychology, Public Policy, and Law, 19, 297-306. DOI: 10.1037/a0033571.

Jundi, S., Vrij, A., Mann, S., Hope, L., Hillman, J., Warmelink, L., \& Gahr, E. (2013a). Who Should I Look At? Eye Contact during Collective Interviewing as a Cue to Deceit. Psychology, Crime \& Law, DOI: 10.1080/1068316X.2013.793332.

Kassin, S.M., \& Gudjonsson, G.H. (2004). The Psychology of Confessions: A Review of the Literature and Issues. Psychological Science in the Public Interest, 5, 33-44. DOI: $10.1111 / j .1529-1006.2004 .00016 . x$

Leal, S., Vrij, A., Warmelink, L., Vernham, Z., \& Fisher, R.P. (2013). You cannot hide your telephone lies: Providing a model statement as an aid to detect deception in insurance telephone calls. Legal and Criminological Psychology, DOI: 10.1111/lcrp.12017.

M'Gloin, J.M., \& Piquero, A.R. (2009). 'I Wasn’t Alone': Collective Behaviour and Violent Delinquency. Australian \& New Zealand Journal of Criminology, 42, 336-353. DOI: 10.1375/acri.42.3.336. 
Meissner, C. A., Redlich, A. D., Bhatt, S., \& Brandon, S. (2012). Interview and Interrogation Methods and their Effects on True and False Confessions. Campbell Systematic Reviews 2012:13. DOI: 10.4073/csr.2012.13.

Rajaram, S., \& Pereira-Pasarin, L.P. (2010). Collaborative Memory: Cognitive Research and Theory. Perspectives on Psychological Science, 5, 649-663. DOI: $10.1177 / 1745691610388763$.

Sacks, H., Schegloff, E.A., \& Jefferson, G. (1974). A Simple Systematics for Organisation of Turn-Taking for Conversation. Language, 50, 696-735. Retrieved from: http://anthro.ucsd.edu/ jhaviland/AudVid/AudVidReadings/Simplest_Systematics_fo r_Turn-Taking_(Language).pdf.

Strömwall, L. A., Granhag, P. A., \& Hartwig, M. (2004). Practitioners' beliefs about deception. In P. A. Granhag \& L. A. Strömwall (Eds.), Deception detection in forensic contexts (pp. 229-250). Cambridge, England: Cambridge University Press.

Strömwall, L.A., Granhag, P.A., \& Jonsson, A.C. (2003). Deception Among Pairs: "Let's Say We Had Lunch and Hope They Will Swallow It!” Psychology, Crime \& Law, 9, 109124. DOI: $10.1080 / 1068316031000116238$.

Van Mastrigt, S.B., \& Farrington, D.P. (2009). Co-offending, Age, Gender and Crime Type: Implications for Criminal Justice Policy. British Journal of Criminology, 49, 552-573. DOI: $10.1093 / \mathrm{bjc} / \mathrm{azp} 021$.

Vernham, Z., Vrij, A., Leal, S., Mann, S., \& Hillman, J. (2014). Collective Interviewing: A transactive memory approach towards identifying signs of truthfulness. Journal of Applied Research in Memory and Cognition, 3, 12-20. DOI: 10.1016/j.jarmac.2014.01.001. 
Vrij, A. (2008). Nonverbal Dominance versus Verbal Accuracy in Lie Detection: A Plea to Change Police Practice. Criminal Justice and Behaviour, 35, 1323-1336. DOI: $10.1177 / 0093854808321530$.

Vrij, A., Akehurst, L., \& Knight, S. (2006). Police officers', social workers', teachers' and the general public's beliefs about deception in children, adolescents and adults. Legal and Criminological Psychology, 11, 297-312. DOI: 10.1348/135532505X60816.

Vrij, A., Evans, H., Akehurst, L., \& Mann, S. (2004). Rapid judgements in assessing verbal and nonverbal cues: Their potential for deception researchers and lie detection. Applied Cognitive Psychology, 18, 283-296. DOI: 10.1002/acp.964.

Vrij, A., Fisher, R., Mann, S., \& Leal, S. (2008). A Cognitive Load Approach to Lie Detection. Journal of Investigative Psychology and Offender Profiling, 5, 39-43. DOI: 10.1002/jip.82.

Vrij, A., Granhag, P. A., \& Mann, S. (2009). Good liars. Open Access Journal of Forensic Psychology, 1, 56-67. Retrieved from: http://www.forensicpsychologyunbound.ws/OAJFP/Volume_1_2009_files/2009excerpt-Vrij.pdf.

Vrij, A., Granhag, P.A., \& Porter, S. (2010b). Pitfalls and Opportunities in Nonverbal and Verbal Lie Detection. Psychological Science in the Public Interest, 11, 89-121. DOI: $10.1177 / 1529100610390861$.

Vrij, A., Jundi, S., Hope, L., Hillman, J., Gahr, E., Leal, S., Warmelink, L., Mann, S., Vernham, Z., \& Granhag, P.A. (2012). Collective Interviewing of Suspects. Journal of Applied Research in Memory and Cognition, 1, 41-44. DOI: 10.1016/j.jarmac.2011.12.002. 
Vrij, A., Leal, S., Granhag, P.A., Mann, S., Fisher, R.P., Hillman, J., \& Sperry, K. (2009). Outsmarting the Liars: The Benefit of Asking Unanticipated Questions. Law and Human Behaviour, 33, 159-166. DOI: 10.1007/s10979-008-9143-y.

Vrij, A., Mann, S., Leal., S., \& Granhag, P.A. (2010a). Getting into the Minds of Pairs of Liars and Truth Tellers: An Examination of Their Strategies. The Open Criminology Journal, 3, 17-22. DOI: 10.2174/1874917801003010017.

Wegner, D. M. (1987). Transactive Memory: A contemporary analysis of the group mind. In B. Mullen \& G. R. Goethals (Eds.), Theories of group behaviour (pp. 185-208). New York: Springer-Verlag.

Woodburn, R., Arnott, L., Newell, A.F., \& Procter, R. (1991). A Study of Conversational Turn-Taking in a Communication Aid for the Disabled. Retrieved from: http://citeseerx.ist.psu.edu/viewdoc/download?doi=10.1.1.50.1876\&rep=rep1\&type=p df.

Zuckerman, M., DePaulo, B.M., \& Rosenthal, R. (1981). Verbal and Nonverbal Communication of Deception. In L.Berkowitz (Ed.), Advances in Experimental Social Psychology (Vol. 14, pp. 1-59). New York: Academic Press. 
Table 1: A list of each of the six interview questions used in this experiment.

\section{Interview Question}

1. 'Can you describe in as much detail as possible how and when you first met. Please give as much information as you can about your first interaction, the location you were at, and so on'.

2. 'Can you describe in as much detail as possible your first date and when this was. Think about the location and the sights and sounds you experienced'.

3. 'Describe your home'.

4. 'Please draw the exterior of your bedroom on this piece of A3 paper... Now describe in as much detail as you can your bedroom starting from the left-hand wall and moving all the way around the outline. Please describe everything including furnishings, decor etc'.

5. 'Describe a recent memorable day that you spent together hour by hour (this must not be your wedding day if you are married)'.

6. 'Can you describe in as much detail as possible your last holiday or trip away together? Please give as much information as you can about the location, what you did, the sights you experienced, and so on'. 
Table 2: Classification results for each of the turn-taking variables when taking total number of swaps into account.

\begin{tabular}{llllll}
\hline Turn-Taking Variable & Chi-square & Wilks' Lambda & Total & Percentage & Percentage \\
& & (significance) & percentage & of truth & of liars \\
& & & of cases & tellers & correctly \\
& & correctly & correctly & classified \\
& & & classified & classified & \\
\hline Continuations per swap & 9.245 & $.809(\mathbf{. 0 0 2})$ & $76.1 \%$ & $79.2 \%$ & $72.7 \%$ \\
Repetitions per swap & 36.122 & $.436(<.001)$ & $84.8 \%$ & $91.7 \%$ & $77.3 \%$ \\
Waiting per swap & 19.457 & $.639(<.001)$ & $82.6 \%$ & $79.2 \%$ & $86.4 \%$ \\
\hline
\end{tabular}


Table 3. Cues used by observers that significantly differed across the three conditions:

\begin{tabular}{|c|c|c|c|c|c|c|c|c|c|}
\hline & \multicolumn{2}{|c|}{$\begin{array}{l}\text { Condition } 1 \\
\text { (non-turn- } \\
\text { taking) }\end{array}$} & \multicolumn{2}{|c|}{$\begin{array}{l}\text { Condition } 2 \\
\text { (turn-taking } \\
\text { control) }\end{array}$} & \multicolumn{2}{|c|}{$\begin{array}{l}\text { Condition } 3 \\
\text { (turn-taking } \\
\text { cues) }\end{array}$} & \multirow[t]{2}{*}{$F$} & \multirow[t]{2}{*}{$p$} & \multirow[t]{2}{*}{$e t a^{2}$} \\
\hline & $M$ & $S D$ & $M$ & $S D$ & $M$ & $S D$ & & & \\
\hline Details & $.97^{b}$ & .18 & $.83^{b}$ & .38 & $.40^{\mathrm{a}}$ & .50 & 18.516 & $<.001$ & .299 \\
\hline Unnecessary details & $.03^{\mathrm{ab}}$ & .18 & $.00^{\mathrm{a}}$ & .00 & $.17^{\mathrm{b}}$ & .38 & 3.955 & .023 & .083 \\
\hline Continuations & $.00^{\mathrm{a}}$ & .00 & $.20^{\mathrm{a}}$ & .41 & $.60^{\mathrm{b}}$ & .50 & 20.300 & $<.001$ & .318 \\
\hline Repetitions & $.00^{\mathrm{a}}$ & .00 & $.03^{\mathrm{a}}$ & .18 & $.50^{\mathrm{b}}$ & .51 & 24.091 & $<.001$ & .356 \\
\hline Waiting & $.17^{\mathrm{a}}$ & .38 & $.07^{\mathrm{a}}$ & .25 & $.63^{\mathrm{b}}$ & .50 & 18.367 & $<.001$ & .297 \\
\hline Consistency & $.13^{\mathrm{ab}}$ & .35 & $.10^{\mathrm{a}}$ & .31 & $.37^{\mathrm{b}}$ & .49 & 4.195 & .018 & .088 \\
\hline
\end{tabular}

Note. Only means (in rows) with different superscript differ significantly from each other ( $p<.05)$ 


\section{Appendix A \\ Examples: Number of Details (Condition 1)}

\section{Truth Telling Pair Example (underlined information = details):}

\section{Describe a recent memorable day that you spent together hour by hour.}

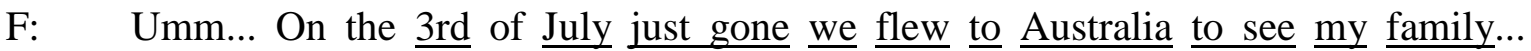
Ermm... we left like the hotel at like $\underline{6}$ in the morning I think, coz our flight was at quarter to 9 . Ermm so we got like one of those shuttle buses from the Hilton to... to... Heathrow... We flew from Heathrow... it was Heathrow wasn't it?

M: Yeah it was Heathrow, it wasn't Gatwick.

F: $\quad$ Terminal 4 .

M: Yep.

F: And then we... I don't remember... I think it was gate $\underline{6}$ we flew from, coz I took a picture of it on my phone.

M: Yeah... but we... I thought we'd have loads of time there, but we really didn't. We had about half an hour in the airport before we had to get on the plane.

F: Which we spent buying stuff for mum (laughs).

M: Yeah! And...

F: Umm...what else? Then we waited there, got on the plane. The food was rubbish... Umm, we had to stop at Brunei... well first Dubai... on the way to Brunei... umm... I think it took 7 and a bit hours to get to Dubai, and then 7 more to get to Brunei, so by that point it was probably...

M: We had to get off the plane, and then go through security again, even though we'd been through security and hadn't left the airport so there didn't really seem like much point... Umm... yeah.

F: I don't really remember...

M: Didn't we have sweet and sour noodles for dinner?

F: $\quad$ Yeah. Sweet and sour noodles and then sweet and sour fried rice on the next flight which was... lovely (laughs). Umm, I can't remember what films we watched though, didn't we watch... that one that we really wanted to see with...

M: $\quad$ Friends...

F: $\quad$ Friends with kids or Friends with children? 
M: Something like that.

F: $\quad$ Yeah. Not friends with benefits, it was a rubbish version of that with kids. Umm... I don't remember now... I don't remember what gate we were in Dubai or Brunei.

M: There was a crab, I remember that, like a little...

F: $\quad$ Oh yeah, yeah in Dubai (laughs).

M: In Dubai like a crab that came and...

F: An alarm clock... (laughs) oh yeah... Umm... what else? We should probably give some more information...

M: $\quad$ Yeah (laughs). Umm...

F: $\quad$ We were at the back of the plane, umm in $\underline{2} \underline{\text { seats }} \underline{\text { on their own coz we didn't want }}$ anyone smelly sitting next to us.

M: (Laughs).

F: But there weren't any toilets near us so we had to like go all the way to the front for the toilet.

M: $\quad$ Yeah... we were in seats $\underline{59 \mathrm{H}}$ and $\underline{59 \mathrm{~K}}$.

F: Yeah, in one row... Umm... oh and we had that bag of Doritos that nearly exploded.

M: Yeah because of the pressure it just kind of...

F: Yeah, we took a picture of it. And you were laughing for like 10 minutes... Umm... we didn't sleep on that flight either because it was our time. 
2. Lying Pair Example (underlined information = details):

Describe a recent memorable day that you spent together hour by hour.

F: $\quad$ Okay... Last Thursday there was this charity thing going on and he got picked as well as Tara to do this um... Bush tucker trial.

M: Yeah so eating creatures...

F: $\quad$ Yeah, it was hilarious (laughs).

M: $\quad$...and weird things and she came down to support me, or so I thought...

F: (Laughs).

M: Instead she was just sitting there, drinking, laughing at me, and yeah...

F: $\quad$ Yeah, so, um... He got drunk from $\underline{4}$ in order to prepare for this...

M: Well I had to drink, I couldn't...

F: $\quad$ So well erm, that was quite funny... I wasn't entirely sure whether he was going to get in. He ate a load of bugs and all those disgusting things, I decided I was not like, going to get ... Was not going to let him kiss me for the rest of that day. Definitely. And err... after that we were both a little bit drunk so we decided to go to $\underline{\text { Pure. Was it Pure? }}$

M: $\quad$ Yeah Pure.

F: $\quad$ Yeah we went to Pure. But there was only a couple of other friends... Was there a couple of other friends? I'm sure...

M: $\quad$ Yeah, $\underline{\text { Hope }}$ and Leanna came down as well...

F: $\quad$ Yeah, Hope and Leanna came down as well. And Hope and Leanna were together, so they were spending most of their time together, so it was nice coz we got to like dance a lot and everything... Together and it was quite crowded which was nice because I prefer crowded places (laughs).

M: To be honest I really enjoy going clubbing quite a lot. But she's not really a clubbing kind of person...

F: $\quad$ Not too much. 


\section{Appendix B \\ Examples: Number of Details (Condition 2):}

1. Truth Telling Pair Example (underlined information = details):

(TT) Can you describe in as much detail as possible your first date.

M: $\quad$ Err... we were in the Winney and Henry in Weymouth where we're from. Umm...

F: $\quad$ Table at the top by the stairs (laughs).

M: $\quad$ Yeah. Umm... Err...

F: $\quad$ Both sat on the outside bit as well.

M: Yeah.

F: They had really tall chairs coz I couldn't sit on it properly coz I'm so short.

M: $\quad$ You had Pepsi...

F: $\quad$ Yeah coz I was driving.

M: $\quad$ Yeah you were driving. And $\underline{\mathrm{Ihad}} \underline{\mathrm{Jack} \text { Daniels }}$ and coke.

\section{If you could carry on for me.}

F: Umm... I think he bought me a drink. Umm... which was nice, coz all of my friends were going 'ooh he really likes you'. Umm...so I was like texting them while he was getting drinks and stuff, saying 'oh he's buying me a drink' and they were all going 'ah yeah I told you so!'

\section{Okay and if you could carry on.}

M: Umm... yeah... And then we just... sat there talking... umm... I... did Jade come along eventually... or not? Or was that a different time?

F: $\quad$ Umm...

\section{And again if you could carry on.}

F: I think she might have done... oh we bumped into someone I think... like someone else that saw us and then... we only stayed there for like, a couple of hours, and then I felt a bit awkward so I was like 'I'm gonna go home', and he expected a lift and I didn't give him one, which I still feel guilty about now (laughs)... Coz that was a bit nasty. 
2. Lying Pair Example (underlined information = details):

(TT) Can you describe in as much detail as possible how you first met.

M: Uhhhh...

F: (Laughs).

M: I don't really remember the first time we properly met... umm... we were at college umm... we were in the common room I remember that much... umm... I think I was messing around with my best friend... umm...

Okay, can I stop you there and can you carry on?

F: $\quad$ Umm... I thought he was a bit of a dick at first soo... I didn't really spend much time with him, I think it was because he was messing around. Umm... I just obviously kind of didn't wanna get too close to him because he was my best friend's boyfriend and not mine...

Okay I'm going to stop you there, and if you could carry on.

M: $\quad$ Ermm... (laughs) Ermm... I don't think we really had much to say to each other... ermm...coz she was my girlfriend's best friend and I didn't really know what to say

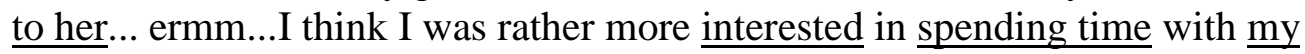
girlfriend at the time....rather than talking to other people.

Okay, and again if you can now carry on.

F: Umm... I don't think it was very long when we first met, I think it was just like, it was in like a break between lessons so it was kind of like... just go and see all your $\underline{\text { friends }}$ and then you have to go... I think it used to be like 15 minutes so... probably didn't say much to him and... just kind of thought 'what a dick', and left (laughs).

\section{And if you can now carry on.}

M: Umm... yeah... I think that's pretty much it. 


\section{Appendix C \\ Examples: Turn-Taking Cues (Condition 3)}

1. Truth Telling Pair Example (italic = continuation; underlined $=$ repetition; bold $=$ waiting):

(TT) Can you describe in as much detail as possible your last holiday or trip away together?

F: $\quad$ Ermm... we went to Australia for 10 weeks to see my family, Buck, my mum, dad, brother, sister and like my uncle and his family. Um... we stayed with them the whole time in Mornington which is near Melbourne. Umm... we didn't really do much coz we didn't have much money, umm so we just helped....

\section{And if you could carry on.}

M: Umm... yeah, err we helped out around the house and umm, looked after her little sister, umm, we... I walked the dogs quite a lot as well umm... and...

\section{If you can carry on for me please.}

F: $\quad$ And the first Sunday we were there it was my little sisters first birthday party that they waited... coz they waited to have the party for us to get there. Umm... and we went... that was like in a little... just a little play barn place. Umm... and then we also went to Melbourne on the train on the Sunday.

\section{I'm gonna interrupt you there...and if you can carry on.}

M: Yeah, we went to Melbourne which was really good ...we got concession tickets on like the public transport coz there wasn't enough room in the car for us and Mia to go... and it was only 6 dollars 50 for like zone 1 and 2 which was like the bus and the train to the city all day so I thought that was pretty good. Umm... and while we were there we ended up walking to this weird museum of like film and games.

Sorry if I can stop you there and if you can carry on.

F: Umm... that was called like... ACMI I think and it was in Federation Square just opposite the train station and it had loads of weird exhibitions of old tellies and all of that... and then a... an Asian woman gave my little sister a balloon coz she was trying to grab it off her... (laughs)

\section{Swap again please.}

M: $\quad$ Yeah, and then we went down toward the train station where we got off and there was a dulux dog there, like a really big fluffy dulux dog... umm and Mia just went mental, like flapping her arms up and down and umm I managed to get quite a few paint samples, not that we needed them... 
2. Lying Pair Example ( italic = continuation; underlined $=$ repetition; bold $=$ waiting $)$ :

\section{(TT) Can you describe in as much detail as possible your last holiday or trip away together?}

M: Well it wasn't just us two it was like a group of our friends from erm... the same halls that we're going to and it was just like a last minute thing, we just decided the night before that we were going to go to Southsea for a barbeque coz the weather was alright and things like that so erm... We woke up quite early and erm me and her ended up going to Tesco's, we just bought a load of meat, different types of meat and a lot of alcohol, and then...

Okay can I swap you now?

F: $\quad$ Yeah err... yeah loads of meat and alcohol (laughs)... and it was... we it was erm... we went off with the others then even though we ended up leaving quite late despite the fact that we got to Tescos quite early because everyone else hadn't got prepared so we had to wait quite a while but when we did go erm, was that the day? Yeah, that was the time we also went to the fair afterwards but anyway first of all when we were at the park, that was really nice we played a bit of football, even though I'm awful at that.

\section{I'm sorry can I swap you again now please?}

M: Yeah so... we played football and we just like chilling, we were eating, drinking, socialising, laughing, it was just, it was like a really good time coz erm we... we... all of us as a group we don't really go out as much, like obviously me and her we see each other all the time but the rest we don't really get to see that much so err...

\section{Can I swap you again?}

F: $\quad$ So it was really nice, we could play more team things and... And erm we played rounders... Was it rounders? Which was also quite embarrassing on my part, and erm, and then after that, was it? I'm sure it was you who was also lobbing around bits of meat from the barbeque and hitting them with the rackets which was disgusting...

M: That weren't me...That was Callum.

F: That was Callum? Oh okay fine that's alright then, you're off the hook with that (laughs) coz that was gross and it landed on my top. And erm...then we went to the fair...

Okay can you swap now please?

M: $\quad$ Err... Yeah so after that we just went to the, to the fair, like to the... like where the arcades are and things like that err we spent a bit of time there and then really from there we kind of, we just came back here and we all decided to go out in the evening as well like to, like one of the places in Guildhall, we started off at, I think at Yates and then we made our way to Babylon. 